\title{
The use of e-learning Course Management Systems to support learning srategies and to improve self- regulated learning
}

\author{
Y. Vovides, S. Sanchez-Alonso, V. Mitropoulou, G. Nickmans
}

\section{Executive Summary}

The adoption of Course Management Systems (CMSs) for web-based instruction continues to increase in today's higher education. A CMS is a software program or integrated platform that contains a series of web-based tools to support a number of activities and course management procedures (Severson, 2004). Examples of Course Management Systems are Blackboard, WebCT, eCollege, Moodle, Desire2Learn, Angel, etc. An argument for the adoption of elearning environments using CMSs is the flexibility of such environments when reaching out to potential learners in remote areas where brick and mortar institutions are non-existent. It is also believed that e-learning environments can have potential added learning benefits and can improve students' and educators' self-regulation skills, in particular their metacognitive skills. In spite of this potential to improve learning by means of using a CMS for the delivery of elearning, the features and functionalities that have been built into these systems are often underutilized. As a consequence, the created learning environments in CMSs do not adequately scaffold learners to improve their self-regulation skills. In order to support the improvement of both the learners' subject matter knowledge and learning strategy application, the e-learning environments within CMSs should be designed to address learners' diversity in terms of learning styles, prior knowledge, culture, and selfregulation skills. Self-regulative learners are learners who can demonstrate 'personal initiative, perseverance and adaptive skill in pursuing learning' (Zimmerman, 2002). Self-regulation requires adequate monitoring strategies and metacognitive skills'.

The created e-learning environments should encourage the application of learners' metacognitive skills by prompting learners to plan, attend to relevant content, and monitor and evaluate their learning. This position paper sets out to inform policy makers, educators, researchers, and others of the importance of a metacognitive elearning approach when designing instruction using Course Management Systems. Such a metacognitive approach will improve the utilization of CMSs to support learners on their path to self-regulation. We argue that a powerful CMS incorporates features and functionalities that can provide extensive scaffolding to learners and support them in becoming self-regulated learners. Finally, we believe that extensive training and support is essential if educators are expected to develop and implement CMSs as powerful learning tools.

\section{The educational technology revolution}

Since the late 1990s, the utilization of CMSs for web-based instruction has steadily increased in higher education. The implementation of CMSs in universities followed on 
the revolution of educational technology that promised better quality, learner-centred education and claimed that it would deliver more independent and active students (Swinney, 2004). E-learning delivered electronic learning materials to distant learners and it was considered to be the new vehicle that would lead education to new learning methods. A recent study in the US shows that among the largest colleges and universities (institutions with a total enrolment of 15,000 or more), more than 96 percent have online course offerings (Allen \& Seaman, 2006). The same study indicates that during fall 2005, about 3.2 million students were enrolled in at least one online course in the US, approximately a million more than in the previous year. These studies show that the educational technology revolution has resulted in an increasing use of CMSs. As a result of this growing integration of CMSs in higher education, the instructors' initial fears that they would eventually be substituted by the CMS were soon replaced by a need for training in the effective use of CMSs. This position paper scrutinizes whether this educational technology revolution has been able to fulfil its promise of learning benefits for instructors and students, and it takes a closer look into the challenges that are related to the implementation of e-learning and CMSs.

\section{The utilisation of Course Management Systems}

The way in which CMSs are being utilized in education differ and are evolving. A CMS can be used as a supplement to the traditional classroom curriculum, i.e., as an electronic repository of course materials. This can be thought of as the 'teleporting' option of the CMS. A hard copy of, for example, the course syllabus is electronically 'transported' or made available in a different place (i.e. the CMS) but remains exactly the same as the paper version of the course syllabus. Many classroom instructors use the CMSs to simply deliver course materials electronically in order to offer students more flexibility in accessing these materials. Instructors who teach in-class courses may also choose to use a 'blended' approach by utilizing the CMS as a tool to deliver additional or supplemental course materials to students. This teaching method is usually called 'blended learning' and the courses are called 'hybrid courses' (Garnham \& Kaleta, 2002). The course is a mixture of traditional teaching environments with elements of e-learning (Nelson, 2003).

Traditional teaching environments tend to be teacher centred; a blended approach allows instructors to mix things up and to offer students a more intellectually engaging learning experience by combining in-class time with online components. Instructors can also implement a true hybrid approach to course delivery by replacing in-class time with online components. This approach allows more flexibility for university administration in, for example, scheduling classrooms; however, the design of hybrid courses requires that instructors have an increased level of comfort or expertise for managing their elearning CMS environment. The e-learning course environment through a CMS offers tools for students to participate in synchronous and asynchronous interaction with each other and with the instructor. Furthermore, students can be more engaged as they can move at their own pace through the course materials, determining their personal needs, etc. (Zhang, Zhao, Zhou \& Numamaker, 2004). Finally, a CMS can be used in distance education for the delivery of fully online courses. For many institutions that offer distance education, the CMS has become the backbone for course delivery. The obvious examples are institutions that offer only fully online courses such as the Open University of Catalonia, the Open University of the Netherlands, and the Open 
University in the UK. But also more traditional universities such as the George Washington University in the US have fully online degrees and courses. In these fully online courses, the instructors' level of expertise in both using the CMS and implementing appropriate instructional strategies is of critical importance in order to design high quality instruction.

In 2003 the Educause Centre for Applied Research studied the faculty use of CMSs. They considered the extent and purpose of use, including the factors on which instructors' decision to use a CMS were based, and whether the use of the CMS resulted in "pedagogical gains" (Morgan, 2003). The study results show that the use of a CMS is increasing at a rapid rate. It is however remarkable that the use is not focused on the interactive features of the CMS but on the content creation tools. The results also indicated that although instructors claimed that they had adopted the CMS in order to meet pedagogical needs, it seemed that the actual use of the system was meeting class management needs instead (Morgan, 2003). This incongruence in actual results versus initial aims is discussed in the next section.

\section{The underutilization of Course Management Systems}

CMSs can provide online access to course materials, assignments, discussions, assessment and grade books, communication and collaboration, registration, records, transcripts, schedules, reports, etc. (Tortora, Sebillo, Vitiello \& D'Ambrosio, 2002). Even though most CMSs have limitations [e.g., browser compatibility issues and template-driven structures (Liu, 2004; Zhang et al., 2004)], current CMSs are incorporating features and functionalities that can provide extensive scaffolding to learners. As promised by the educational technology revolution, CMSs can support learner-centred activities, system interactivity, and personalized and flexible instruction, and it can provide immediate feedback (Zhang et al., 2004). However, further research findings also revealed that the use of CMS by students is problematic when the systems' features do not function properly. These features, as referred to by Abbitt (2005), are: good framework/design, implementation (compatibility/reuse), tailored curriculum/intelligent analysis, high availability, and security.

Despite this potential of the CMS to scaffold learners, it seems that many instructors currently use CMSs simply as a delivery mechanism for the subject matter. The integrated features and functionalities, such as the capabilities to present the learning material content in multimedia ways, are often underutilized. This underutilization may not impact the learning of in-class students but it may have a negative effect on the learning of distant students enrolled in fully online courses. As a result, the CMS neither scaffolds the students' autonomy, nor does it encourage their initiative for managing their own learning processes (Boekaerts, 1997).

According to the Dual Coding Theory, multiple content representations enhance memory recalls. This theory, first proposed by Paivio (1986), claims that the human brain consists of two separate cognitive coding centres: one for processing and storing the visual incoming information, and another for the visualisation and storage of the verbal incoming information. Incoming information is stored twice, in two different cognitive systems, and, when it is recalled, it is drawn simultaneously from the visual and the verbal centre. This multiple content representation enhances the recall and the 
processing of information. Research results reported by Paivio support that when information is presented in the form of pairs (picture-picture, texttext, picture-text), answering time to a question is shortest when the information was presented as a picture-picture pair and longest for text-text pairs (Paivio, 1986). Although these results indicate that presenting information in the form of pairs is more effective for the processing and recall of information, it seems that many educators (even if they make use of a CMS for their subject matter) still present the content as only text. This traditional working method does not promote student interactivity, engagement with the content, or learning. On the contrary, it gradually reduces the interests of the students and leads them to confusion and frustration (Zhang et al., 2004).

Besides this underutilisation of the multiple content representation options of a CMS, research has also shown that the web-based communication tools that are embedded in CMSs, like discussion forums, chat and e-mail, are underutilized by students and teachers (Nelson, 2003). The most frequently used communication tool is e-mail, but it is mainly used for personal correspondence among the students. Communication between instructor and student is very limited (Nelson, 2003). When teachers use the communication tools of a CMS, they prefer to use them in order to support communication on course management issues rather than to support communication on instructional tasks. This illustrates that the pedagogical aspect of CMSs is underexploited since the use of the communication tools does not support the development of metacognitive skills (planning, self-regulation, self-evaluation; Nelson, 2003). Metacognitive skills are critical in one's ability to manage the learning process and to engage in online inquiry. Bransford, Brown \& Cocking (1999) found that effective learners are, compared to average learners, more aware of their strengths and weaknesses and improve their learning skills by thinking through problems, understanding situations, and making decisions. Many researchers have proposed that cognitive and metacognitive strategies instruction can result in improved learning when learners consciously apply these strategies (Bielaczyc, Pirolli \& Brown, 1995;

Weinstein \& Meyer, 1994). Strong metacognitive skills help learners to plan, monitor, and evaluate their learning process and thus allow a self-reflective approach to the learning process itself. We discuss this in more detail in the following section.

\section{Using Course Management Systems as learning tools}

The underutilization of CMSs, by both instructors and learners, results in a lack of robustness to offer extensive support for learning (Mitrovic, Suraweera, Martin \& Weerasinghe, 2004; Swenson and Curtis, 2004; Dabbagh, 2004). Learners lacking in key metacognitive and selfregulatory skills will not learn much from open-ended learning environments without the implementation of scaffolds to help them along (Azevedo, 2005). Jones, Farquhar \& Surry (1995) suggest that with improved learner awareness of metacognitive knowledge, learning efficacy could also be enhanced. In this section, we take a closer look at individualised learning and reflective learning. These are two important ingredients that can enhance a CMS as a tool that supports learning and instruction offering the necessary scaffolds for the development of metacognitive and self-regulatory skills.

Instructors in the 1980s started to teach their students how to use cognitive strategies to improve their learning. However, studies by Boekaerts (1997) show that the instruction 
of learning strategies in the long term does not always result in self-regulated learning. Moreover, learning strategies applied and practiced in a particular context do not produce the same results in a different context. According to Boekaerts (1997), instruction of learning strategies should go hand in hand with instructional support in order to motivate the students and help them to regulate their learning.

In addition to the students' self-regulation skills, students' critical thinking skills also need improvement. The preliminary findings of a study completed by the Educational Testing Service involving over 6.000 students, indicate that in terms of information and communication technology (ICT) skills, many students do not possess the critical thinking skills to demonstrate success in informational management and research tasks (Bogan, 2006). In fact, only 52 percent of the students who took the ICT assessment evaluated the objectivity of a website when searching for information and only 44 percent was able to identify a research statement for a class assignment that addressed the demands of the assignment (Bogan, 2006).

Students' needs vary, and instructional support needs to be personalized because what one student may perceive as providing 'low autonomy' may be considered as 'highly structured' by another. Consequently, different kinds of design for instructional support are needed, adapted to the different needs and characteristics of the students. This implies that the structural design of a CMS should incorporate instructional support that allows both inexperienced students and students who are more experienced in learning online to improve their self-regulation skills. The design of a CMS should take into account both the cognitive and affective domain to enhance self-regulation (McMahon, 2002; Boekaerts, 1997). In essence, the scaffolds within a CMS need to be adaptive in order to foster student self-regulation in these open-ended learning environments (Azevedo, 2005).

As suggested by Boekaerts (1997), the e-learning environment in a CMS should provide opportunities for students to learn how to: "select, combine, coordinate their cognitive strategies in connection to the new knowledge, and prompted to reflect on their strategy use, extending their metacognitive knowledge with strategy and capacity beliefs" (Boekaerts, 1997). Despite this strong recommendation, the CMS is often used as a 'one size fits all' service to learners, irrespective of their knowledge level, goals, and interests. All students have access to the same instructional material and the same webbased tools without personalized support (Brusilovksky, 2004). All students receive the same exercises irrespective of their pre-existing knowledge and experience. It is not taken into consideration that the educational material is presented to a large number of learners who have varied knowledge levels, skills, and learning strategies.

Current CMSs do incorporate the options that allow instructors to, to a certain degree, customize and personalize the learning experience. For example, the Blackboard Learning System includes a function called 'adaptive release' whereby the instructor can customize the learning experience of students. In order to be a powerful learning instrument, these built-in functionalities of CMSs should be fully exploited to offer students a flexible and adaptable learning experience based on the individual student's learning skills. (Darbamulla \& Lawhead, 2004). In fully online courses, where a hypermedia approach to instruction is followed, learners need to be able to direct their own learning to achieve the learning goals. According to Torrano Montalvo and Gonzalez Torres (2004), self-regulated learners know how to plan, control, and direct 
their mental processes towards the achievement of personal goals. To become a selfregulated learner, the student requires metacognitive skills and adequate monitoring strategies, which many learners may not already possess.

This position paper addresses the need for the development of an e-learning environment within a CMS that addresses learners' diversity in terms of metacognitive skills, learning styles, prior knowledge, and cultures. A flexible and adequately utilized CMS can offer new technology-based opportunities to personalize instructional support in education that we believe will challenge traditional methods of pedagogy and benefit the learning process. The integration of an intelligent tutor agent that will take in consideration each learner's profile and thus help students search and collect information in order to answer their questions during the learning process should be considered (Nunes \& Labidi, 2002). It is important to note that we are not proposing simply an individualized path to instruction but suggesting ways to allow students to personalize and customize their learning experience.

\section{A metacognitive approach to CMSs}

There are several models on metacognition that have contributed to the design of instructorindependent programs. In this section, we briefly review four of these models. In the next section we take a closer look at a new instructional design paradigm for webbased instruction. We suggest a metacognitive approach to the design of CMSs in the 8th section of this paper.

Nelson-Narens Framework (Nelson \& Narens, 1990) .- The Nelson-Narens framework addresses the process of learning. It describes learning as a cyclical, iterative process between the cognitive processes that take place at the object level (information processing operations) and the processes at the meta level (overseeing operations). For instance, when learners are faced with new content, they engage in metacognitive monitoring by implementing strategies that allow them to encode, rehearse, retrieve, etc. what they consider to be important content. Then, at the meta level, during metacognitive control, the learners make adjustments to what they think they ought to be learning and compare their perceived degree of learning with the desired degree of learning. The assumption is that a selfregulated learner will continue to study a particular content item if their perceived degree of learning is below the desired degree because self-regulated learners are able to apply metacognitive control through selfreflection in order to assess their learning progress and adjust the processing of the information to meet the set learning goals (Nelson \& Narens, 1994). We see the NelsonNarens Framework as the umbrella framework for the metacognitive model of the instructional design process (Figure 1, section 7) for the development of instructional materials that inherently incorporate metacognitive skill enhancement tools.

COPES (Winne \& Hadwin, 1998) .- Existing research on metacognition and study strategies indicates that metacognitive knowledge about cognitive strategies improves recall for a particular content (Winne \& Hadwin, 1998). In COPES, products such as the definition of the study task, the enabling plan, etc. can be considered as part of the object level within the Nelson-Narens Framework. Through metacognitive monitoring the outcome of an assessment about the content item that is being studied serves as a feedback mechanism and allows learners to adjust their learning accordingly 
(metacognitive control). This implies that formative assessment should be part of instruction because the outcome of formative assessment allows learners to engage in monitoring and control, that is the iterative process between the object and meta levels, without the pressure of obtaining good grades. The COPES model states that formative assessment is a critical aspect of the instructional design process.

Metacognitive framework ( $\mathrm{Lin}, \mathbf{2 0 0 1}$ ) .- The framework by Lin conceptualizes metacognitive activities, such as domain-specific knowledge and knowledge about the self-as-learner. Lin emphasizes the need for metacognitive supports to be included in learning environments. The focus of this framework is on the design of these learning environments, particularly on the design of metacognitive support and the content that is included in such designs. Lin's framework describes the use of modelling and prompting as well as the interaction between the self-as-learner and the social environment via social modelling. Lin concludes that for strategy training it is necessary to develop students' selfknowledge and to instruct domain-specific strategies at the same time. 'Communities of metacognitive practice' (face-to-face or virtual) play an important role in the creation of supportive social environments in order to foster metacognition for domain-specific knowledge. Collaboration and communication are key elements for self-assessment and reflection within such communities. Metacognitive reflection relies, in terms of its occurrences within the design, on group collaboration and on the multiple perspectives involved in that interaction. Role-play and metacognitive discourses on learning activities to foster self-reflection are considered as key strategies in designing supportive metacognitive social environments for developing the self-aslearner (Lin, 2001).

Theoretical framework of self-regulated learning (Dunlonsky \& Hertzog, 1998) .Schunk \& Zimmerman (1994) defined self-regulated learning as "the process whereby students activate and sustain cognitions and affects, that are systematically oriented toward attainment of their goals". Cognitive self-regulation can be taught to students (Hwang \& Liu, 1994; Torrance, Fidalgo, \& Garcia, 2005). CMSs should inspire, motivate, and guide students to develop selfregulated learning cognitive skills. This means that students are guided to play an active role in learning, become self-organized, self-directed, and independent, and actively participate in the learning process to construct their knowledge. According to the constructivist theory, students will utilise open applications to construct more complicated meanings. However, as indicated earlier in this paper, not all learners are able to manage their learning process and master the content at hand, especially in e-learning environments. This is where CMSs can provide the support to guide learners in the use of the appropriate tools to help them acquire, for example, the strategic knowledge to collect and organize data and then demonstrate what they have learned (Niederhauser \& Stoddart 2001).

The following section outlines the use of learning objects and metadata in CMSs for the purpose of providing an adaptive learning environment that could support learners' by helping them enhance and apply their metacognitive skills.

\section{Learning objects and metadata in Course Management Systems}

Learning objects can be considered as the basis of a new instructional design paradigm for webbased instruction. Learning technologies based on this model emphasize reuse 
as the key characteristic of the learning contents and activities. The definition by Polsani, highlights the importance of reuse: "A Learning Object is an independent and self-standing unit of learning content that is predisposed to reuse in multiple instructional context." (Polsani, 2003) The idea of reusing resources for learning is as old as learning itself. Books and other physical learning materials have always been reusable. However, the notion of reusability in the learning object paradigm needs to be understood as part of a digital world, particularly from a World Wide Web perspective. The ease of reproducing digital materials in exact form, and making them instantly available worldwide, introduces a new form of reuse, qualitatively as well as quantitatively different from any previous form. Learning resources can now be reused repeatedly with the aim of conforming more complex resources, which in turn are more costeffective to produce (Downes, 2001). Nevertheless, the mere use of existing webbased contents is not new. Consequently, we find it necessary to reflect on the differential characteristics that justify the consideration of this new paradigm of learning objects, and not only on the paradigm itself.

There are at least two relevant features when considering the reuse of learning objects for a metacognitive approach to design within CMSs:

o Learning objects reuse is based on the creation and use of metadata, that is to say, external descriptions of the learning resources themselves. Without metadata, learning objects would not bring any novelty or added value.

o Learning object metadata, if provided in adequate languages, can provide support for the development of new technological tools aimed at facilitating a number of tasks such as learning objects search, retrieval and management.

Thus, the metadata are at the heart of the learning objects. Other definitions of the term 'learning object' for example, the definitions by Sosteric and Hesemeier (2002) and Hamel and Ryan-Jones (2002), also emphasize the necessity of including metadata with the learning object. Without this component we would be talking about the design of digital learning resources in a general sense. Metadata are consequently a fundamental element in the paradigm of learning objects. In fact, a digital resource with an excellent pedagogical design is not, per se, a good learning object, and will only be considered a good learning object if its metadata are of quality. Metadata can facilitate operations, such as search based on the metadata information, aggregation of learning objects, etc. In contrast, metadata have no quality if they do not provide any useful information that can contribute to a better management of the learning object itself. For example, a yogurt label that only says 'yogurt' might provide useful information, but the label will be much more useful when it also provides information about the flavour, nutritional composition, and expiry date. This information will be much more helpful to identify the yogurt that corresponds to an individual's needs. A person who is, for example, allergic to certain food substances will not be able to select a yogurt based on the first label but will be able to make a correct decision when considering the second label.

Learning objects are currently being used as central or complementary elements in the context of e-learning and in other areas of learning and instruction. The mode of integration of these resources with a set of other formative elements provided to learners, even though very diverse, consists frequently of the selection of those learning objects that experts (tutors, instructors, instructional designers, etc.) consider most 
appropriate for a specific type of learner. With this decision, experts take into account the learner characteristics such as age, prior knowledge, or the level of education. The existence of metadata that describe the content of the learning objects is of utmost importance in this model, as the decision of choosing one learning object over another is based on the metadata of each object at the time of the selection. A software system that enables the management and delivery of learning content and resources to students, a CMS, gives support to a number of activities and course procedures mentioned earlier in this paper.

If educational materials were designed in the form of reusable learning objects, CMSs could even bring new interesting possibilities such as the interaction between different CMSs or the interchange of learning objects created and designed by different organizations. Even further, CMSs might well infer information from the metadata records of the learning objects with the objective of -in an automated or semiautomated way- selecting and recommending certain activities for learners to perform. If the goal of a learning activity is to enhance the student's metacognitive skills, the selection of the most appropriate learning objects will be based on the current metacognitive status of the learner and on the metacognitive skills desired. For instance, after performing an assessment that indicates a certain level of metacognitive skill, the CMS would be able to recommend one or more learning activities (in the form of learning objects) in order to improve those metacognitive skills. This decision would be, of course, based on the metadata of all the available learning objects. Metadata provide learning object users with a medium to search, define, and find data in which they are interested. Consequently, in a context where instructional materials are in the form of learning objects, CMSs could implement new features to take advantage of the benefits of qualitative metadata, e.g. recommending appropriate metacognitive activities, or allowing students and tutors to perform activities such as content analysis, information resource location, or enhanced searches, to name a few.

\section{Characteristics of a metacognitive CMS}

According to the instructional principles of constructivism, two basic design elements are suggested for CMSs (Niederhausen \& Stoddart, 2001):

1. The first element concerns the determination of the authentic activity. This involves the issue of how the student will handle the obtained information in order to transfer the newly acquired skill to the real world.

2. The second element is the increasing refinement of strategies, e.g. the teaching methodology to proceed from simple to complex. The students initially are introduced to a simplified environment of which all complicated elements are abstracted. After experiencing this simplified environment, gradually more complicated elements are added. The last stage is functioning in the 'authentic' (or real) environment.

Inspired by the metacognitive models that were discussed in the 5th section of this paper and the instructional design paradigm of learning objects, discussed in the 6th section, we propose a metacognitive approach to e-learning design. Figure 1 shows the proposed e-learning hypermedia design metacognitive approach that integrates the meta and object levels (Nelson-Narens Framework) form the umbrella framework. Under the object level we identify strategies that learners will need to apply as they learn new 
content. If learners do not possess these skills then learning strategy training becomes necessary. Through communities of practice learners can engage in reflective learning as they learn domain-specific content. In addition, they can engage in self-evaluation of the quality of their learning and through strategies such as modelling and prompting the learners can monitor and adapt their strategies to better their learning outcomes.

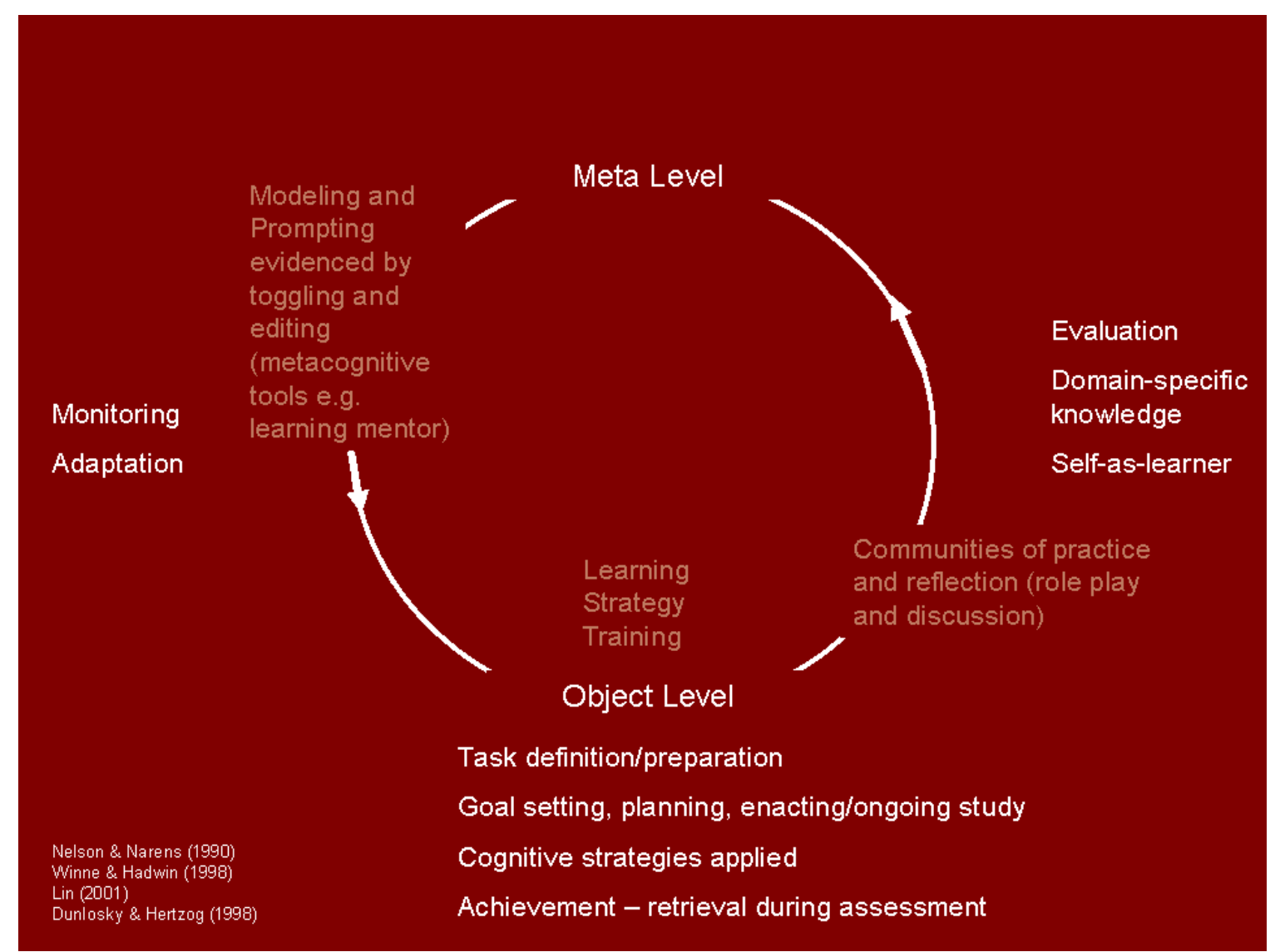

Figure 1: e-learning hypermedia design metacognitive approach

We argue for a CMS that includes functionality that offers 'stop and think' triggers as learners interact with the e-learning course content. These triggers can be implemented as 'feedback loops' to help learners toggle and adapt their cognitive strategies as they learn new content (Dunlosky \& Hertzog, 1998; Winne \& Hadwin, 1998). Finding ways to observe learners' toggling and adapting of their learning strategies during the learning process is an expression of self-regulated, active learning. This type of observation through feedback loops needs to be part of the metacognitive e-learning CMS or at a minimum part of an e-learning course environment. The monitoring of the feedback outputs from task preparation, ongoing study and retrieval could have direct effects on test performance, such as influencing the self-paced study or retrieval. On the other hand, they can also have more indirect, long-term effects on test performance, for instance influencing a person's metacognitive knowledge (Dunlosky \& Hertzog, 1998).

Features of the CMS that can help students to become self-regulated learners include the adaptive release of content within e-learning courses. This enables the learner to experience an individualized learning path. Adaptive release of content also allows the instructor to create rules for delivering content to the learner upon mastery of specific tasks leading to the achievement of the course learning objectives. It can be implemented with prompts and cues that encourage learners to think about their 
learning process and to utilize appropriate learning strategies, in essence developing the learners' metacognitive skills. The way in which these types of features are integrated into the course is crucial to guarantee that the learners are using their metacognitive skills and managing their e-learning. The institute of Higher Education Policy identified certain features that a CMS should incorporate in order to deliver successful online courses including the availability, reliability of technology, standards of course design, and instructor training. Additionally, Abitt (2005) proposes five factors that he calls 'the pillars of quality' of a web-based CMS. These include learning effectiveness, student satisfaction, faculty satisfaction, cost effectiveness, and access. A powerful CMS should be reliable and flexible and support a learner-centred pedagogy. It should incorporate challenges and opportunities for students to engage in active learning, to receive immediate feedback, to perform matches between materials, and to monitor, review, and evaluate course materials. It should promote interactivity between students on one hand and between student and instructor on the other. It also should provide easy access and navigation options and tools to students (Abitt, 2005). With the metacognitive approach in mind (Figure 1), the CMS environment needs to incorporate opportunities for learner self-reflection for both the subject matter and the learning process.

\section{The role of the instructor in a metacognitive CMS environment}

The new educational technology environment of CMSs shifts the focus of the learning experience from the instructor to the instructor's role as a guide, coordinator, facilitator and coach of the learning process. The instructor monitors the student and provides guidance when necessary during the learning activities. Besides this 'new' pedagogical role, the instructor will need technical support, assistance and training in order to gain knowledge and skills on how a CMS can be utilised using its full potential for learning and assessment outcomes. Learning to use technology to design instruction requires much more than learning to select a specific set of tools. It is crucial that instructors are trained and supported to acquire the 'new' pedagogical role (that of facilitator/coach) and the implementation advantages they can offer to educational technology (Severson, 2004). This will be necessary to allow instructors to efficiently embed pedagogy to structure their course content and to choose the web-based communication tools that fit best into the pedagogical framework. When pedagogical approaches to teaching are consistent with the technology, the efforts to use the technology are more likely to yield positive results (Nelson, 2003). As a consequence, it is essential that instructors have in mind both technology and pedagogy when designing their course content and assignments for CMS delivery.

However, instructors may not have the necessary skills or the time to develop e-learning instructional materials and learning objects or learning the nuances of the CMS use it effectively for instruction. Acquiring technological skills is not easy, and many instructors get discouraged by the effort to produce online courses when they lack technical knowledge such elements as programming, designing of asynchronous course activities, preparing and evaluating exercise sheets, creating and maintaining student score lists, etc. (Nelson, 2003). Training and support is absolutely essential if instructors are expected to develop and implement CMSs as powerful learning tools. 


\section{Conclusion: Educational policy requirements for the development and implementation of powerful CMS systems}

CMSs are often underutilised and this results in an overall underestimation of these instruments to support learning and instruction. E-learning environments within a CMS should address learners' diversity in terms of metacognitive skills, learning styles, prior knowledge, and cultures. A metacognitive approach to the design and use of CMS can offer new opportunities to personalise instructional support in education, can challenge traditional methods of pedagogy, and eventually benefit the learning process. In order to stimulate the use of the CMS as a powerful learning tool instead of a mere delivery mechanism of content, higher education institutions need to develop an overall support mechanism and service team for the use of the CMS itself. This support team should be composed of instructional designers, graphic designers, multimedia specialists, programmers, and information system specialists who are responsible for the faculty development, e-learning course materials design and development, the maintenance and service of the CMS hardware, software, and network. Instructors should be trained (via seminars, tutorials, conferences, etc.) on how to use CMSs to design effective e-learning environments and how to make the best use of the features of the CMS. Furthermore, they should be supported to embed pedagogy and new administrative directives into their instruction with educational technology (Severson, 2004).

The George Washington University is in the process of implementing customizable elearning templates for use by instructors that already account for the metacognitive design elements shown in Figure 1. While reviewing a template design to decide whether to customize it and how instructors also engage in a self-reflective process of their own course design, an exercise that many may not otherwise do. The days when "e-learning" was viewed as nothing more than creating PowerPoint slides are over. We should instead create content in the form of learning objects with metadata so that we can allow for the possibility of a more powerful and robust CMS that can include new features and functionalities such as intelligent learning mentors or tutors that will make CMSs more attractive and useful to users.

\section{References}

Abitt, J. (2005). The Development of an Evaluation Framework for a Web-Based Course Management System in Higher Education. Thesis submitted to University of Idaho for the degree of Doctor of Philosophy (May 2005).

Allen, E., \& Seaman, J. (2006). Making the Grade: Online Education in the United States. Retrieved November 30, 2006 from http://www.sloanc.org/publications/survey/pdf/making_the_grade.pdf

Azevedo, R. (2005). Using Hypermedia as a Metacognitive Tool for Enhancing Student Learning? The Role of Self-regulated Learning. Educational Psychologist, 40 (4), 199209.

Boekaerts, M.(1997). Self-regulated Learning: A New Concept Embraced by Researchers, Policy Makers, Educators, Teachers, and Students. Learning and Instruction, 7(2), 161-186. 
Bielaczyc, K., Pirolli, P. L., \& Brown, A. L. (1995). Training in Self-Explanation and Self-Regulation Strategies: Investigating the Effects of Knowledge Acquisition Activities on Problem Solving. Cognition and Instruction, 13 (2), 221-252.

Bogan, K. (2006). College Students Fall Short in Demonstrating the ICT Literacy Skills Necessary for Success in College and the Workplace.

Bransford, J., Brown, A. L., \& Cocking, R. R. (Eds.). (1999). How People Learn: Brain, Mind, Experience, and School. Committee on Developments in the Science of Learning, Commission on Behavioural and Social Sciences and Education. National Research Council.

Brusilovsky, P. (2004). Knowledge Tree : A Distributed Architecture for Adaptive ELearning. In Proceedings from the World Wide Web conference 2004 (pp. 104-113). New York, USA.

Dabbagh, N. (2004). Pushing the envelope: Designing authentic learning activities using Course Management Systems. In Proceedings of World Conference on E-Learning in Corporate, Government, Healthcare, and Higher Education 2004 (pp. 1155-1159). Washington DC, USA.

Darbhamulla, R., \& Lawhead, P. (2004). Paving the Way Towards an Efficient Learning Management System. In Proceedings of the Association for Computing Machinery South East conference 2004 (pp. 428-433). Huntsville, Alabama, USA.

Downes, S. (2001). Learning objects: Resources for distance education worldwide. International Review of Research in Open and Distance Education, 2 (1).

Dunlosky, J., \& Hertzog, C. (1998). Training programs to improve learning in Later Adulthood: Helping Older Adults Educate Themselves. In D.J. Hacker, J. Dunlosky, \& A. C. Graesser (Eds.), Metacognition in Educational Theory and Practice (pp. 249-275). Mahwah, NJ: Lawrence Erlbaum Associates.

Garnham, C., \& Kaleta, R. (2002). Introduction to hybrid courses. Teaching with Technology Today, 8 (10). Retrieved January, 20, 2007, from http://www.uwsa.edu/ttt/articles/garnham.htm

Hamel, C.J. \& Ryan-Jones, D. (2002). Designing Instruction with Learning Objects. International Journal of Educational Technology, 3(1).

Hwang, B., \& Liu, Y. (1994). A study of proportional reasoning and self-regulation instruction on students' conceptual change in conceptions of solution. ED368574.

Jones, M. G., Farquhar, J. D., \& Surry D. W. (1995). Using Metacognitive Theories to Design User Interfaces for Computer-based Learning. Educational Technology, 35, 12 22.

Lin, X. (2001). Designing Metacognitive Activities. Educational Technology Research and Development, 49 (2), 23-40. 
Liu, Y. (2004). Faculty Development and CMS. In Proceedings of Society for Information Technology in Teacher Education International Conference 2004 (pp. 2409-2412). Atlanta, GA.

McMahon, M. (2002). Designing an on-line environment to scaffold cognitive selfregulation. In A. Goody, J. Herrington, \& M. Northcote (Eds.), Proceedings of the 2002 Annual International Conference of the Higher Education Research and Development Society of Australasia (HERDSA) [Online conference proceedings]. Available: http://www.herdsa.org.au/publications/

Mitrovic, A., Suraweera, P., Martin, B., \& Weerasinghe, A. (2004). DB-Suite:

Experiences with Three Intelligent, Web-Based Database Tutors. Journal of Interactive Learning Research, 15 (4), 409-432.

Morgan G. (2003). Faculty Use of Course Management Systems. Retrieved January 20. 2007 from http://www.educause.edu/ir/library/pdf/ers0302/rs/ers0302w.pdf

Nelson, T. O., \& Narens, L. (1994). Why investigate metacognition? In J. Metcalfe, \& A. P. Shimamura (Eds.), Metacognition: Knowing About Knowing (pp. 1-25). Cambridge:Massachusetts Institute of Technology.

Nelson, T. O., \& Narens, L. (1990). Metamemory: a theoretical framework and new findings. The Psychology of Learning and Motivation, 26, 125-173.

Nelson, J. (2003). Integration of Course Management System Communication Tools in Instruction. Thesis submitted to the University of Tennessee, Knoxville for the degree of Doctor of Philosophy (December 2003).

Niederhauser, D., \& Stoddart, T. (2001). Teacher's instructional perspectives and use of educational software. Teacher \& Teacher Education, 17, 15-31.

Nunes, H., \& Labidi, S. (2002). Mobile Agents for Information Extraction in Mathnet System. In Proceedings of the 32nd ASEE/IEEE Frontiers in Education Conference 2002 (F2E-20-F2E-25). Boston, USA.

Paivio, A. (1986). Mental representations: A dual coding approach. New York: Oxford University Press.

Polsani, P. R. (2003). Use and Abuse of Reusable Learning Objects. Journal of Digital Information, 3(4). Retrieved September 21, 2003 from http://jodi.ecs.soton.ac.uk/Articles/v03/i04/Polsani/.

Schunk, D., \& Zimmerman, B. (1994). Self-regulation of learning and performance. Issues and educational applications. Hillsdale, NJ: Eribaum.

Severson, A. (2004). Faculty Support Required for the Implementation of a New Learning Management System. Thesis submitted to the Simon Fraser University for the degree of Master in Distributed Learning (June 2004). 
Sosteric, M. \& Hesemeier, S. (2002). When is a Learning Object not an Object: A first step towards a theory of learning objects. International Review of Research in Open and Distance Learning, 3(2).

Swenson, P., \& Curtis, L. (2004). Course Management Systems to Learning Enhancement Systems a Necessary Evolutionary Step in Online Education. In Proceedings of Society for

Information Technology and Teacher Education International Conference 2004, (pp. 717-721). Atlanta, GA.

Swinney, L.A. (2004). Why Faculty use a Course Management System (Blackboard) to Supplement their Teaching of Traditional Undergraduate Courses. Thesis submitted to the University of North Dakota for the degree of Doctor of Philosophy (December 2004).

Torrance, M., Fidalgo, R., \& Garcia, J. N. (in press). The teachability and effectiveness of strategies for cognitive self-regulation in sixth grade writers. Learning and Instruction.

Torrano Montalvo, F., \& Gonzalez Torres, M. C. (2004). Self-Regulated Learning: Current and Future Directions. Electronic Journal of Research in Educational Psychology, 2 (1), 1-34.

Tortora, G., Sebillo, M., Vitiello, G., \& D' ambrosio, P. (2002). A Multilevel Learning Management System. In Proceedings of the fourteenth International Conference on Software Engineering and Knowledge Engineering 2002, (pp. 541-547). Ischia, Italy.

Weinstein, C. E., \& Meyer, D. K. (1994). Learning strategies, teaching and testing. In T. Husen \& T. N. Postlethwaite (Eds.), The International Encyclopaedia of Education (2nd ed.). Oxford: Pergamon Press.

Winne, P. H., \& Hadwin, A. F. (1998). Studying as Self-Regulated Learning. In D.J. Hacker, J. Dunlosky, \& A. C. Graesser (Eds.), Metacognition in Educational Theory and Practice (pp.277-304). Mahwah, NJ: Lawrence Erlbaum Associates.

Zhang, D., Zhao, J., Zhou, L., \& Numamaker, J. (2004). Can E-Learning Replace Classroom Learning? Communication of the ACM, 47(5), 75-78.

Zimmerman, B.J. (2002). Becoming a self-regulated learner: An overview. Theory into Practice, 41 (2), 64-70. 